\title{
Extracellular matrix of the developing ovarian follicle
}

\author{
Raymond J. Rodgers, Helen F. Irving-Rodgers and Darryl L. Russell \\ Reproductive Medicine Unit, Department of Obstetrics and Gynaecology, University of Adelaide, \\ South Australia 5005, Australia
}

\begin{abstract}
Ovaries can be considered tissues in which endocrine organs - follicles and corpora lutea continually grow and regress. Follicles have both epithelial and stromal layers in which cell migration or movement, cell division, specialization and differentiation, and death occur. A fluid-filled antrum develops and at ovulation the epithelial cells undergo an epithelial to mesenchymal transition into luteal cells. Although growth factors and hormones are very important in some of these processes, the extracellular matrix participates in all of them. Importantly, the matrix is diverse in composition and cells rarely behave without reference to the composition and structure of the matrix. When follicles commence growing, the follicular basal lamina changes in its composition from containing all six $\alpha$ chains of collagen type IV to only $\alpha 1$ and $\alpha 2$. Perlecan and nidogen 1 subsequently become components of the follicular basal lamina, and there is an increase in the amount of laminin chains $\alpha 1, \beta 2$ and $\gamma 1$, at least in cows. Late in follicular developent and on atresia some follicles contain laminin $\alpha 2$. On atresia the follicular basal lamina is not degraded as occurs at ovulation, but can be breached by cells from the thecal layer if granulosa cells no longer align it. Other matrix components are present and also change during follicular development. Versican was identified in all the follicular layers and has been found to play a key role together with inter- $\alpha$-trypsin inhibitor, tumour necrosis factor $\alpha$-stimulated gene 6 (TSG-6) and hyaluronan in cumulus oocyte expansion and fertility. Recent studies are directed at investigating the regulation of the matrix and its function in the ovary.
\end{abstract}

The adult ovary contains a fixed reserve of inactive primordial follicles. It is clear that in some species, but apparently not all (Antczak and van Blerkom, 2000), primordial follicles develop in fetal life from dividing oogonia and ovigorous cords invaginating from the surface epithelium (Sawyer et al., 2002). Even at this early stage these cords are separated from the surrounding stroma by a basal lamina. The cords then 'bud' into primordial follicles, each containing a small non-growing oocyte and a layer of non-dividing pregranulosa cells encapsulated by the follicular basal lamina. Once formed, a small number of these primordial follicles is activated daily by unknown mechanisms, the oocyte commences growing and the granulosa cells begin to divide. As the granulosa cells divide, the number of cell layers (called the membrana granulosa or follicular epithelium) around the oocyte increases, and the basal lamina expands (for reviews, see Rodgers et al., 1999a, 2001). Later in development a fluid-filled cavity or antrum develops within the follicles (antral stage). As the follicle grows, a specialized cell population surrounding the oocytes (cumulus cells)

Email: ray.rodgers@adelaide.edu.au differentiates from the membrana granulosa and the zona pellucida matrix develops around the oocyte. Specialized stromal layers, theca interna and externa, develop. The membrana granulosa of each ovarian follicle is encapsulated by a follicular basal lamina separating it from the surrounding stromal elements in primordial follicles or from the theca interna in antral follicles. In healthy follicles it excludes capillaries, white blood cells and nerve processes from the granulosa compartment until ovulation, at which time the basal lamina is degraded as the follicles develop into corpora lutea. During the process of ovulation a new hyaluronan-rich matrix critical for fertility forms within the cumulus-oocyte complex (COC).

These temporary endocrine units within the adult ovary (follicles and corpora lutea) continually develop and regress, thus giving rise to the day-to-day variation in hormone secretion by the ovary. The formation of follicles and corpora lutea requires tissue remodelling, cellular replication and specialization. Ovarian cells respond to external stimuli that signal changes in gene regulation, growth or differentiation. Considerable research effort has been directed at how hormones and growth factors regulate such processes. Recently, research efforts have 
Table 1. Composition of different basal laminae in the ovarian follicle wall in cows

\begin{tabular}{|c|c|c|c|c|c|}
\hline Matrix & $\begin{array}{l}\text { Developmental } \\
\text { stage }\end{array}$ & Laminins & Collagens & Other components & Reference \\
\hline \multirow[t]{4}{*}{$\begin{array}{l}\text { Follicular basal } \\
\text { lamina }\end{array}$} & Primordial & $\alpha 1, \beta 2, \gamma 1$ & $\begin{array}{l}\text { Type IV } \alpha 1, \alpha 2 \\
\quad \alpha 3, \alpha 4, \alpha 5, \alpha 6\end{array}$ & & $\begin{array}{l}\text { Van Wezel et al., 1998; } \\
\quad \text { Rodgers HF et al., } 1998\end{array}$ \\
\hline & Preantral & $\alpha 1, \beta 2, \gamma 1$ & $\begin{array}{l}\text { Type IV } \alpha 1, \alpha 2 \\
\quad \alpha 3, \alpha 4, \alpha 5, \alpha 6\end{array}$ & Nidogen, perlecan & $\begin{array}{l}\text { Van Wezel et al., 1998; } \\
\text { Rodgers HF et al., 1998; } \\
\text { McArthur et al., } 2000\end{array}$ \\
\hline & Antral & $\alpha 1, \beta 2, \gamma 1$ & Type IV $\alpha 1, \alpha 2$ & Nidogen, perlecan & $\begin{array}{l}\text { Van Wezel et al., 1998; } \\
\text { Rodgers HF et al., 1998; } \\
\text { McArthur et al., } 2000\end{array}$ \\
\hline & Atretic, antral & $\begin{array}{l}\alpha 1, \beta 2, \gamma 1 \\
\quad+/-\alpha 2\end{array}$ & Type IV $\alpha 1, \alpha 2$, & Nidogen, perlecan & $\begin{array}{l}\text { Van Wezel et al., 1998; } \\
\text { Rodgers HF et al., 1998; } \\
\text { McArthur et al., 2000; } \\
\text { Irving-Rodgers et al., } 2002\end{array}$ \\
\hline $\begin{array}{l}\text { Call-Exner } \\
\text { bodies }\end{array}$ & Preantral & $\alpha 1, \beta 2, \gamma 1$ & $\begin{array}{l}\text { Type IV } \alpha 1, \alpha 2 \\
\quad \alpha 3, \alpha 4, \alpha 5, \alpha 6\end{array}$ & Nidogen, perlecan & $\begin{array}{l}\text { McArthur et al., 2000; } \\
\quad \text { van Wezel et al., } 1999\end{array}$ \\
\hline $\begin{array}{l}\text { Thecal sub- } \\
\text { endothelial } \\
\text { basal lamina }\end{array}$ & Antral & $\beta 1, \beta 2$ & Type IV $\alpha 1, \alpha 2$ & & $\begin{array}{l}\text { Van Wezel et al., 1998; } \\
\quad \text { Rodgers HF et al., } 1998\end{array}$ \\
\hline $\begin{array}{l}\text { Thecal arteriole } \\
\text { smooth muscle } \\
\text { basal lamina }\end{array}$ & Antral & $\beta 2$ & Type IV $\alpha 1$, $\alpha 2$ & & $\begin{array}{l}\text { Van Wezel et al., 1998; } \\
\quad \text { Rodgers HF et al., } 1998\end{array}$ \\
\hline
\end{tabular}

been directed at the composition (summarized in Table 1) and roles of extracellular matrix in these processes (Luck, 1994; Rodgers RJ et al., 1998, 1999b, 2000). Cell-matrix interactions can signal important contextual information to which cells respond either directly or indirectly by modulating their responses to other stimuli. The expectation of researchers in this area is that the follicular matrix will be instrumental in controlling all aspects of cellular and tissue biology during follicle growth and atresia. This article attempts to review the literature as it relates to follicle development.

\section{Extracellular matrix is important for follicle development}

The extracellular matrix has many different roles (Hay, 1991). These include effects on cell shape and behaviour, such as migration, division, differentiation, cell death and cell anchorage. All these behaviours occur in follicle development. The matrix can play a role in the fluid dynamics of a tissue, either providing osmotic forces which could be important for follicular fluid formation, or filtering soluble materials, which could occur across the follicular basal lamina. The matrix can provide rigid or elastic mechanical support for tissues. In addition, nutrients and hormones and other extracellular signals are often required to traverse the matrix in order to reach target cells. The matrix has the ability to bind growth factors including those found in follicles. Binding can be either direct in the case of fibroblast growth factor 2 (FGF-2) or indirect with insulin-like growth factor I (IGF-I) or activin, where binding proteins (BP) 2 and 5 or follistatin bind to the matrix. In essence, the extracellular matrix defines or rather provides specialized microenvironments. It thus determines both cell and tissue function. It is not surprising then that the extracellular matrix is generally a diverse mixture of components, and that the composition of the matrix is important.

\section{Turnover and degradation of the extracellular matrix}

During follicle development, continual remodelling of the follicular wall occurs as the follicle enlarges. In particular, turnover of structural collagens of the theca externa and in nearby stroma and tunica allow for expansion of the follicle. The follicular basal lamina must also expand with follicle growth. The extent of vasculature within the theca layers must also increase to keep up with follicle enlargement, and this probably involves all three mechanisms of angiogenesis: sprouting, intussusception and elongation. Hence, the vasculature-associated matrix must also increase. These processes of matrix turnover require discrete control as the final result is an expansion of the matrix, not a total degradation. The precise mechanism by which this occurs is not well understood, but clearly involves simultaneous degradation and synthesis of the matrix. Enzymes involved in matrix degradation, including matrix metalloproteinases 1, 2, 9, and 13; tissue inhibitor of metalloproteinases 1 and 2; tissue plasminogen activator; urokinase plasminogen activator; and 
plasminogen activator inhibitor 1 , have been studied in the ovary and recently reviewed by Smith et al. (1999) and by Curry and Osteen (2001). The roles of many of these enzymes in ovulation, a process that involves marked changes in tissue structure as the follicle redevelops into a corpus luteum, and in the COC (D'Alessandris et al., 2001), have been studied. These areas will not be reviewed here.

\section{Extracellular matrix of the membrana granulosa}

Basal laminae are specialized sheets of extracellular matrix which in epithelia underlie the epithelial cells and separate them from adjoining stroma (for reviews, see Timpl, 1989; Yurchenco and Schittny, 1990; Paulsson, 1992; Weber, 1992; Timpl and Brown, 1996). They influence epithelial cell proliferation and differentiation, and can selectively retard the passage of molecules. Basal laminae are composed of a lattice-type network of collagen type IV intertwined with a network of laminin. This structure is stabilized by the binding of entactin or nidogen to the collagen and laminin. The heparan sulphate proteoglycan perlecan and other molecules are associated with the collagen type IV-laminin backbone. Importantly, basal laminae in different regions of the body differ in the ratio of all these components. Furthermore, each 'component' is a class of several components. For example each molecule of collagen type IV comprises three $\alpha$ chains. However, there are six different chains of collagen type IV $\alpha(\alpha 1-\alpha 6$, each encoded by a separate gene) (Hay, 1991). As only three of these $\alpha$ chains are required to make one collagen molecule, many potential different combinations of type IV collagen can be made. Some of these different combinations have been observed in nature (for example $\alpha 1 \alpha 1 \alpha 2, \alpha 3 \alpha 4 \alpha 5$ ), and each combination can be regarded as different (Sado et al., 1998). Similarly, each laminin molecule is composed of three chains; one $\alpha$ (A in the old nomenclature), one $\beta$ (B1 in the old nomenclature) and one $\gamma$ (B2 in the old nomenclature) chain. There are five different $\alpha$ chains, three $\beta$ chains and three $\gamma$ chains (all encoded by separate genes) giving rise to $45(5 \times 3 \times 3)$ potential different combinations, and many of these combinations have been observed in nature. Thus, much complexity in the composition of basal lamina can be generated just by the types of laminin and collagen type IV alone. It is now recognized that the unique composition of each basal lamina contributes to its specific functional properties.

\section{The follicular basal lamina}

On the basis of the roles of basal laminae in other tissues and organs it can be speculated that the follicular basal lamina is important for maintaining the polarity and the extent of specialization of granulosa cells that align the follicular basal lamina (Luck, 1994; Rodgers et al., 2000). However, polarity studies of the membrana granulosa have not been undertaken, unlike many other epithelia. Studies on the changing nature of the follicular basal lamina together with follicle phenotype have been undertaken and are discussed below. However, there are very few studies attempting to show that these changes in the basal lamina bring about changes in cell and tissue behaviour during follicle development.

\section{Selective filtration by the follicular basal lamina}

The follicular basal lamina probably has a role in retarding entry of larger molecular weight plasma proteins and molecules (for example low density lipoproteins) into the follicular antrum. Conversely, if the flow of material in the other direction is similarly retarded, the follicular basal lamina may trap large molecules (for example some proteoglycans) synthesized by granulosa cells and oocytes in the follicular fluid. The molecular mass cut off is calculated to be 100-500 kDa based upon comparisons of the composition of follicular fluid with that of plasma (Shalgi et al., 1973). This does not necessarily indicate the limit imposed by the follicular basal lamina only, as plasma proteins also have to traverse the vascular sub-endothelial basal lamina before reaching the follicular antrum.

Size may not be the only determinant of movement across the follicular basal lamina. It has been shown that the blood-follicle barrier to movement of inter- $\alpha$ trypsin inhibitor is due to its negative charge (Hess et al., 1998), indicating that the follicular basal lamina may also exclude this material on this basis. The follicular basal lamina also contains the heparan sulphate proteoglycan perlecan (McArthur et al., 2000). Heparan sulphate proteoglycans can bind a number of growth factors (for example FGF2), or their binding proteins (for example follistatin, and IGFBP2 and 5). Thus, it is possible that the follicular basal lamina may also restrict the movement of growth factors. Certainly the molecular exclusion capability of the follicular basal lamina allows it to determine in part the milieu of factors to which granulosa cells and the oocyte are exposed.

\section{Matrix interactions with granulosa cells}

A number of studies on the effects of the components of basal laminae and other extracellular matrix components have been undertaken by a number of workers in a variety of species. One model ideal for studying effects of the follicular basal lamina on granulosa cells is that of chicken follicles. Methods for isolating the follicular basal lamina of chickens have been available since the late 1970s (Gilbert et al., 1977) but it is only recently that it has been used for this purpose (Asem et al., 2002). In addition, other components of basal lamina are available commercially: laminin $1(\alpha 1 \beta 1 \gamma 1)$ and laminin $2(\alpha 2 \beta 1 \gamma 1)$, and even an assembled laminin 1 matrix (Matrigel). These have been used to determine effects of 


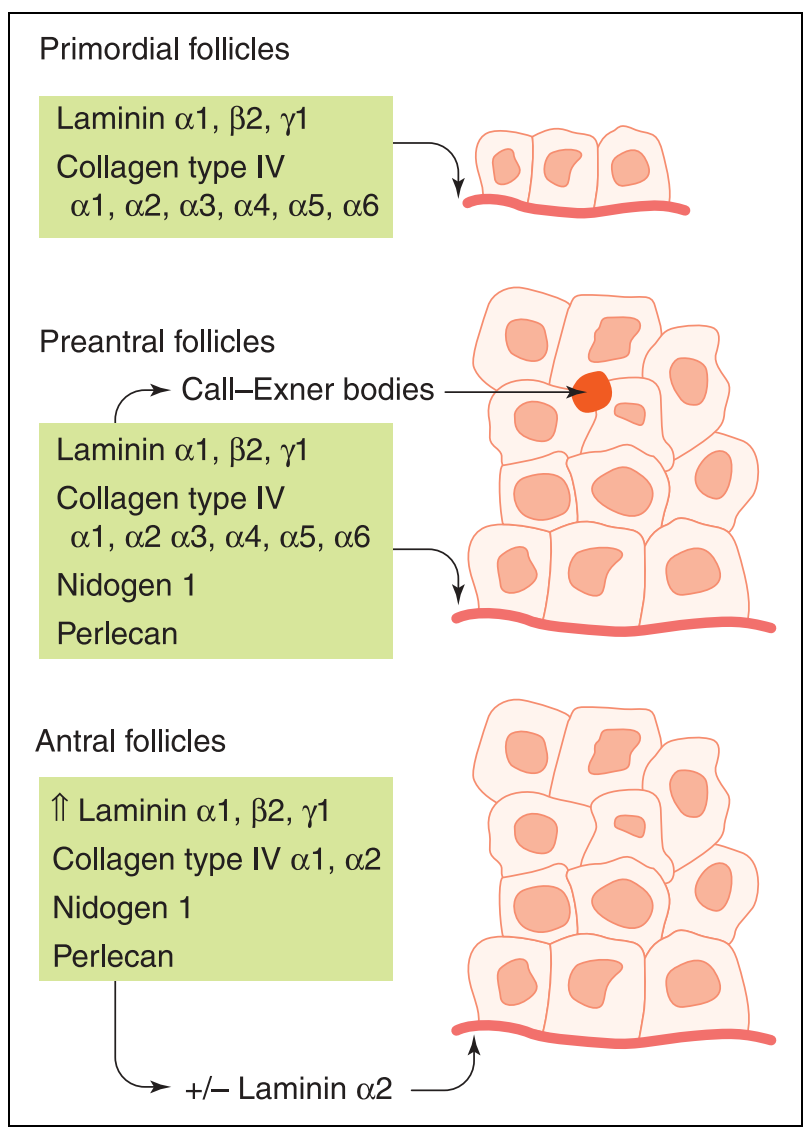

Fig. 1. The components of the follicular basal lamina and the Call-Exner bodies at different stages of follicular development. The downward arrows indicate that these components are probably derived from granulosa cells, and the laminin $\alpha 2$ is probably derived from the theca. $+/-$ indicates that expression of laminin $\alpha 2$ is sometimes present and sometimes absent from antral follicles.

these components on follicular cells in culture. However, it is the components of laminin $3(\alpha 1 \beta 2 \gamma 1)$ that are present in the follicular basal lamina (Rodgers et al., 1999b, 2000). Other matrix molecules (for example collagens to coat surfaces or three-dimensional matrices, vitronectin, fibronectin, peptides containing cellular attachment sequences) are available for culturing granulosa cells but none of these truly represent the appropriate matrix to mimic that found in vivo.

Cells interact with the matrix through cell-surface adhesion receptors including the integrins. Integrins are heterodimeric glycoproteins composed of $\alpha$ and $\beta$ subunits. Over $17 \alpha$ and eight $\beta$ subunits are known, producing over 23 different heterodimeric combinations (Belkin and Step, 2000). Additional molecules within the cell associate with integrins in order for a complex molecular cell-matrix junction to form. These junctions or 'focal adhesions' can transduce multiple intracellular signals as well as provide the cells with anchorage. However, it is not simply a ligand-receptor interaction that determines the effects of the matrix on cells. Only a few integrins have been localized to granulosa cells: $\alpha 6 \beta 1$ in non-luteinized granulosa cells (Fujiwara et al., 1997; Le Bellego et al., 2002) and $\alpha 2$ and $\alpha 5$ in luteinizing cells. Tetraspanins also interact with the integrins as part of the process by which the matrix links with intracellular signalling molecules, and indeed one of the most highly expressed proteins in granulosa cells from ovulating follicles was identified long ago (CD63, ME491; Rapp et al., 1990).

\section{Changing composition of the follicular basal lamina}

In follicles, the basal lamina expands in surface area during follicular development and its composition changes as it does so (Rodgers RJ et al., 1998, 1999b, 2000) (Fig. 1). In bovine follicles, expression of collagen type IV $\alpha 3$ to $\alpha 6$ declines during growth whereas $\alpha 1$ and $\alpha 2$ continue to be expressed (Rodgers HF et al., 1998). Studies in rats also found a decline in collagen type IV $\alpha 3$, but were able to detect type IV collagen $\alpha 4$ and $\alpha 5$ in large follicles (Frojdman et al., 1998). Laminin $\beta 1$ is transiently expressed at the preantral stage, and $\alpha 1, \beta 2$ and $\gamma 1$ appear to be more highly expressed in preantral and antral follicles (Fig. 2; van Wezel et al., 1998). Expression of laminin $\alpha 1$ in rats has been detected. The expression of $\alpha 1, \beta 2$ and $\gamma 1$ in cows indicates that laminin $3(\alpha 1 \beta 2 \gamma 1)$ is present in the follicular basal lamina. Assembled laminin 3 has been isolated only from placenta (Champliaud et al., 2000), and hence it is tempting to make the association between laminin 3 expression and steroid hormone synthesis as cause and effect. However, it has not yet been shown that $\alpha 1, \beta 2$ and $\gamma 1$ are assembled together into a laminin molecule in the follicular basal lamina, and in the absence of studies of other laminin subunits (namely $\alpha 3, \alpha 4, \alpha 5$, $\beta 3, \gamma 2$ or $\gamma 3$ which could complex with the $\alpha 1, \beta 2$ or $\gamma 1$ giving rise to different laminin isoforms), it remains to be confirmed which laminin molecule(s) is present in the follicular basal lamina. Nidogen 1 and perlecan are not detectable in primordial follicles but are expressed later in follicular development (McArthur et al., 2000). Laminin $\alpha 2$ is very unusual; it is expressed only in a few healthy antral follicles (van Wezel et al., 1998; IrvingRodgers et al., 2002).

From these studies it is clear that during follicle development the follicular basal lamina becomes less collagenous and more laminin rich. Such basal laminae by the nature of the different bonds between laminins and collagens are more expandable; this is required for follicle enlargement. It is not clear what the effects of loss of collagen type IV $\alpha 3-\alpha 6$ may have on the function of the follicular basal lamina. The lack of expression of nidogen in primoridial follicles might at first appear perplexing because its role is to cross-link collagens and laminins, both of which are present in primoridial follicles. However, a second nidogen (Miosge et al., 2002) has been identified and localization studies 

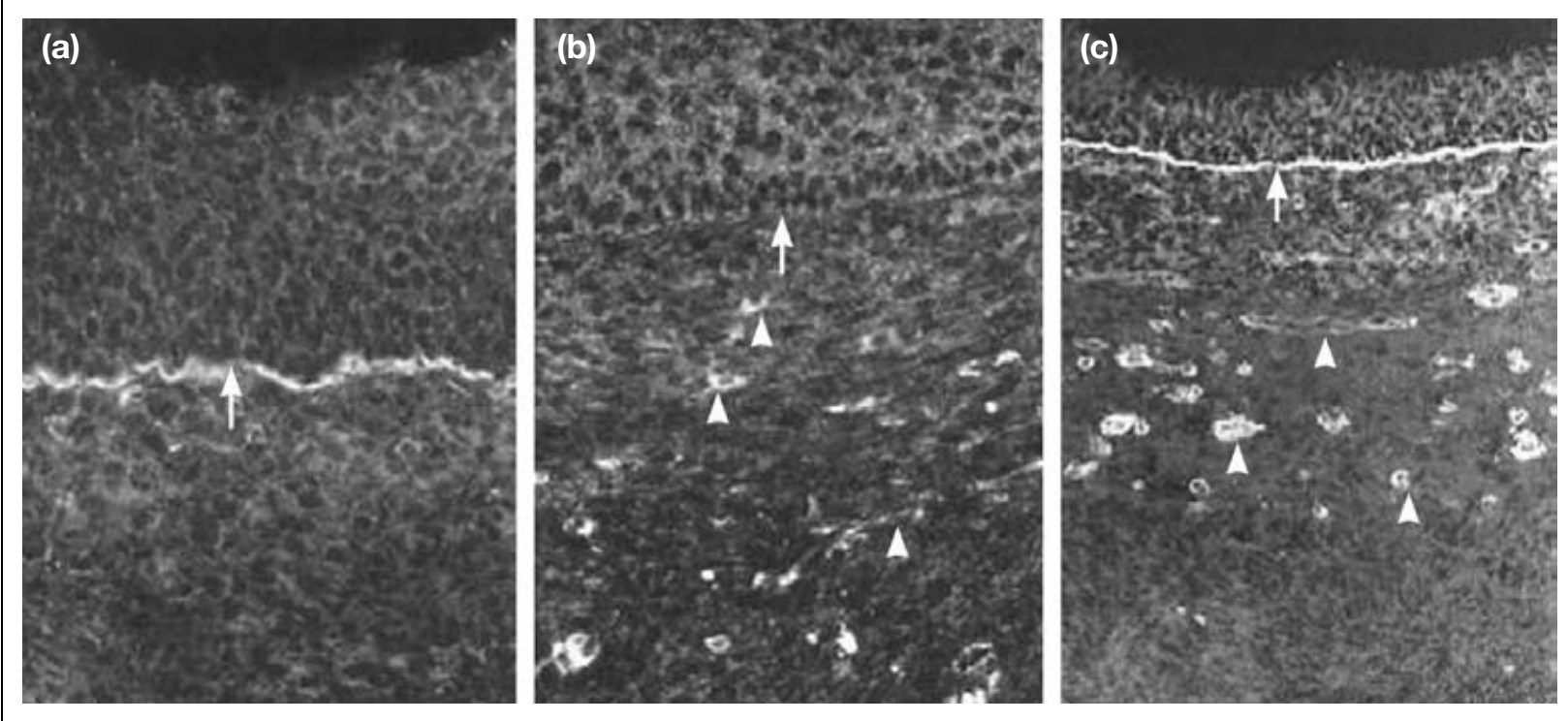

Fig. 2. Immunofluorescent localization of individual laminin chains to healthy bovine antral follicles. (a) Positive staining in the follicular basal lamina for the $\alpha 1$ chain but (b) no detectable $\beta 1$ chain, although the thecal vasculature stains positively. (c) Both the follicular basal lamina and vasculature stain positively for the $\beta 2$ chain. Arrows indicate the position of the follicular basal laminae. Arrowheads represent blood vessels (van Wezel et al., 1998).

have yet to be performed. Upregulation of the heparan sulphate proteoglycan perlecan may be one of the more significant changes occurring during early follicular development, as it can bind a number of growth factors. Thus, certain growth factors could more freely cross the follicular basal lamina in primordial follicles than in growing follicles when perlecan is present in the follicular basal lamina. It should be stressed that these comments are speculative and have not been definitively shown.

\section{The cellular origin of the follicular basal lamina}

Although immunolocalization of matrix components has been extremely useful at localizing to their specific site in the follicle wall, it is not a useful technique in identifying which cells synthesized each component. In situ hybridization would be the ideal investigative tool but will need to be treated with caution because some genes are very similar to other family members, potentially leading to cross-hybridization. Other types of RNA analyses using isolated cells or tissues could potentially be confounded by cross-contamination of cells. Hence, it is not surprising that studies of the origins of the follicular extracellular matrix are not well advanced.

Both fibronectin and laminin $\gamma 1$ chain have been shown to be expressed by granulosa cells (Carnegie, 1990; Zhao and Luck, 1995). Evidence of the origins of other components of follicular basal lamina comes indirectly from identifying the components of Call-Exner bodies. These bodies are similar in ultrastructure to basal lamina and have been observed within the membrana granulosa of follicles in vivo. This finding indicates that they are synthesized by granulosa cells, and hence so too might be the follicular basal lamina. Collagen type IV chains $\alpha 1, \alpha 2, \alpha 3, \alpha 4$, and $\alpha 5$ and the laminin $\alpha 1, \beta 2$ and $\gamma 1$ subunits and perlecan and nidogen 1 have been localized to Call-Exner bodies (van Wezel et al., 1999; McArthur et al., 2000) in cows and laminin $\alpha 1$ in rats (Frojdman et al., 1995). On further follicular development, the basal lamina material of Call-Exner bodies changes in regard to the apparent ratio of collagen type IV to laminin, similar to that which occurs in the follicular basal lamina (Rodgers et al., 2000). Granulosa cells cultured under anchorage-independent conditions can also synthesize a basal lamina, which at least contains collagen type IV and fibronectin (Rodgers et al., 1995, 1996). Hence, most of the components of the follicular basal lamina are probably synthesized by the granulosa cells.

Whether there is a contribution to the follicular basal lamina from the theca in larger follicles, or indeed the stroma surrounding preantral follicles, is not known. One candidate component is laminin $\alpha 2$. In other tissues, where it is a component of an epithelial basal lamina, it appears to originate from the stroma (Sorokin et al., 1997; Lefebvre et al., 1999). In bovine follicles, laminin $\alpha 2$ is expressed only in a very small proportion of healthy follicles but more commonly in atretic follicles (Fig. 3) (Irving-Rodgers et al., 2002). The expression pattern of this laminin chain is also different from that of the other molecules in the follicular basal lamina, and could be explained by a different cellular origin. Laminin $\alpha 2$ is also 

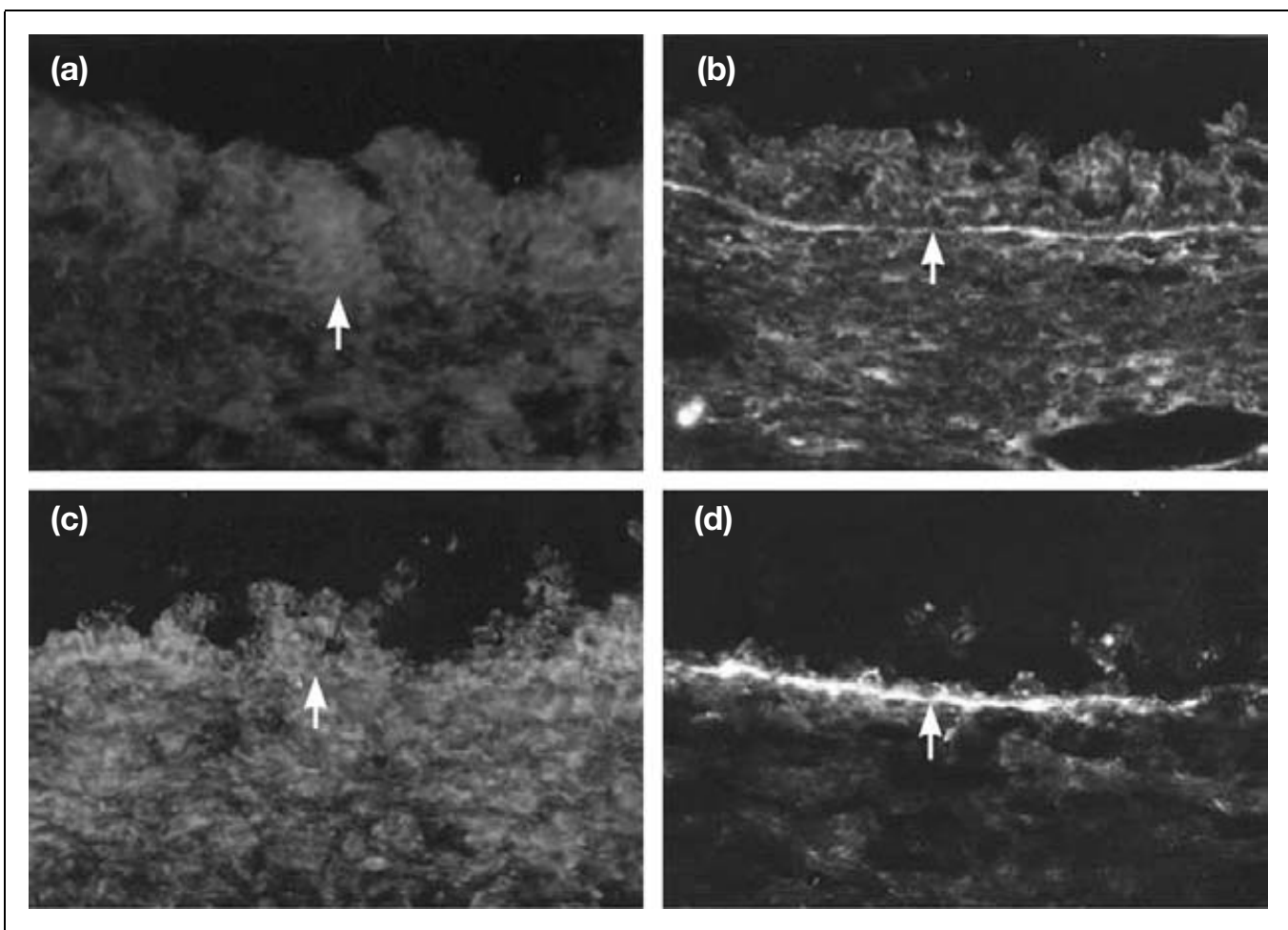

Fig. 3. Immunolocalization of laminin $\alpha 2$ in (a) healthy $(2 \mathrm{~mm})$ or (c) antral atretic $(4.5 \mathrm{~mm})$ bovine follicles, which do not have detectable staining; and (b) early antral $(4 \mathrm{~mm})$ and (d) late antral $(3.5 \mathrm{~mm})$ atretic follicles (Irving-Rodgers et al., 2001), which stain positively. Arrows indicate the position of the follicular basal laminae (Irving-Rodgers et al., 2002).

not present in the Call-Exner bodies (van Wezel et al., 1999), and hence it is likely to be derived from the thecal layer and not granulosa cells. The role of laminin $\alpha 2$ in follicle development is at this stage perplexing.

\section{The follicular basal lamina and atresia}

The event of atresia that occurs in follicles is unusual in the body because it eventually involves complete destruction of the epithelial layer by death of all the epithelial cells. In other epithelia, such as luminal gut epithelium or involuting glands, cells undergo apoptosis as they age, but this is regional and involves only a few cells at any one time, and not normally the entire epithelial layer.

Histochemical observations of bovine and ovine follicles undergoing atresia have identified laminin chains, perlecan, nidogen and collagen type IV chains (Huet et al., 1997; Irving-Rodgers et al., 2002). In these studies, the components identified in atretic follicles were the same as present in the class of follicles from which they were derived, except for laminin $\alpha 2$, the expression of which also did not correlate with the type or severity of atresia (Fig. 3; Irving-Rodgers et al., 2002). As follicles shrink upon atresia, folding of the basal lamina occurs. This is quite different from what happens to

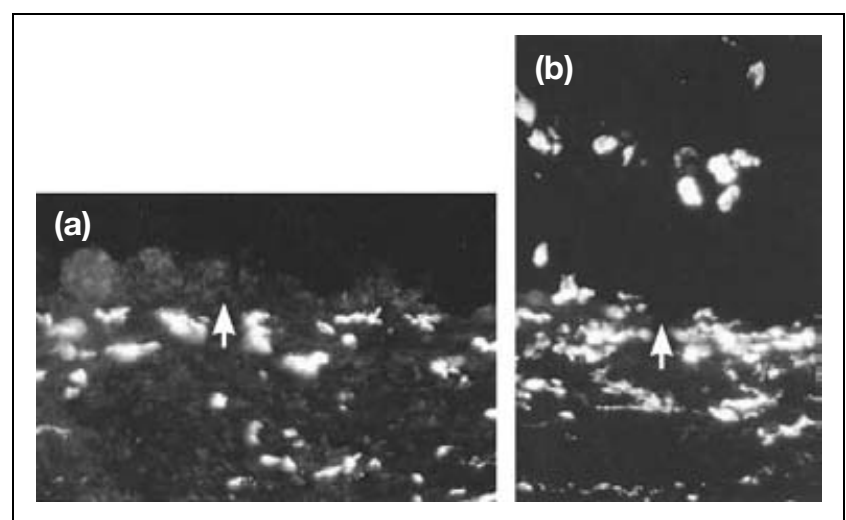

Fig. 4. Immunofluorescent localization of macrophage marker CD-68 in (a) antral $(3 \mathrm{~mm})$ and (b) basal $(4 \mathrm{~mm})$ atretic bovine follicles (Irving-Rodgers et al., 2001). Arrows indicate the position of the follicular basal laminae. Macrophages have breached the follicular basal lamina in the basal atretic follicles but not the antral atretic follicles.

the follicular basal lamina upon ovulation where it is extensively degraded. Even though the follicular basal lamina survives the early events of atresia, macrophages, endothelial cells and fibroblasts can breach the follicular basal lamina (Fig. 4) as they migrate from the thecal 
layer of atretic follicles (Irving-Rodgers et al., 2001). However, movement of cells from the thecal side across the basal lamina is restricted whilst it is aligned with healthy granulosa cells.

\section{Follicular fluid}

Granulosa cells of antral follicles are bathed in follicular fluid containing proteins and soluble extracellular matrix molecules including proteoglycans. Proteoglycans consist of a core protein with attached glycosaminoglycans. The composition of follicular fluid has been analysed for glycosaminoglycans and the synthesis of the glycosaminoglycans by granulosa cells has been studied by Yanagishita, Hascall and colleagues over decades. However, it is only recently that the proteoglycans from which the glycosaminoglycans are derived have been identified. Two proteoglycans, verscian and perlecan, were identified in human follicular fluid aspirated from patients undergoing oocyte retrieval in an IVF programme (Eriksen et al., 1999). These two proteoglycans as well as decorin were identified in homogenates of whole bovine follicles (McArthur et al., 2000). However, perlecan is probably not a component of follicular fluid, as it was found to be a component of the follicular wall (McArthur et al., 2000), and may have been a contaminate in the follicular fluid in the study by Eriksen et al. (1999). Decorin is a component of the stroma (H. F. Irving-Rodgers and R. J. Rodgers, unpublished) and one of its roles is to associate with fibrillar collagens. Perlecan has been discussed above.

Versican, on the other hand, is likely to be synthesized in the membrana granulosa (and also theca) and it could potentially have a number of roles in follicular development. At its $\mathrm{N}$ terminal it contains a G1 domain that can bind hyaluronan and may participate in cellmatrix and cell-cell interactions. The G3 domain at the C-terminal end contains a number of motifs (lectin-like, epidermal growth factor-like, and compliment binding). Between these two domains are two alternatively spliced regions where the glysoaminoglycan chains are attached. Splicing in this region produces four isoforms (V0, V1, V2, V3), which therefore have different degrees of glycosaminoglycan substitution. V0/V1 and V3 isoforms have been detected in the ovaries of mice and rats and V0/V1 expression was localized to granulosa cells (Russell et al., 2003). In addition, a disintegrin and metalloproteinase with thrombospondin motifs (ADAMTS-1) can proteolytically cleave versican (Sandy et al., 2001). Hyaluronan has also been identified in follicular fluid, indicating that it too may have a role in follicle development, separate from its well-studied role in expansion of the COC. Hyaluronan is a glycosaminoglycan that lacks a core protein. It is produced by granulosa and cumulus cells (Salustri et al., 1992; Schoenfelder and Einspanier, 2003) and is present in follicular fluid. The roles of hyaluronan and versican in follicular fluid remain to be determined, but given their roles in other organs, it could be speculated that they are integral for follicular fluid formation.

\section{Extracellular matrix of the oocyte and cumulus cells}

The production of hyaluronan by cumulus cells has also been well studied owing to its role in expanding the COC in ovulating follicles, and this continues to be a dynamic area of research. Hyaluronan is assembled at the cell surface by a hyaluronan synthase. Three of these genes have been identified and hyaluronan synthase 2 is expressed by cumulus cells responding to the ovulatory LH surge (Fulop et al., 1997a; Kimura et al., 2002; Schoenfelder and Einspanier, 2003). A number of hyaluronan-binding proteins (hyaladherins) have also been identified, which in follicles include versican (Eriksen et al., 1999; McArthur et al., 2000, Russell et al., 2003), link protein (Sun et al., 2002), tumour necrosis factor $\alpha$-stimulated gene 6 (TSG-6) (Fulop et al., 1997b; Yoshioka et al., 2000; Mukhopadhyay et al., 2001) and members of the inter- $\alpha$-trypsin inhibitor heavy chain family (Odun et al., 2002). Inter- $\alpha$-trypsin inhibitor is a complex set of molecules derived from serum. It contains bikunin, produced in the liver from an mRNA transcript encoding both bikunin and $\alpha_{2}$-microglobulin and having the protease inhibitor function of inter- $\alpha$ trypsin inhibitor. Bikunin attaches to heavy chains 1,2 , or 3 (also known as serum-derived hyaluronan-associated proteins or SHAPs) via its chondroitin sulphate side chain. In some species, serum-derived inter- $\alpha$-trypsin inhibitor crosses the follicular basal lamina after the LH surge (Powers et al., 1995) and becomes covalently crosslinked to hyaluronan, releasing free bikunin in the process and stabilizing the expanding cumulus matrix (Chen et al., 1996; Hess et al., 1999). Thus, cumulus expansion when performed in vitro requires the presence of serum or inter- $\alpha$-trypsin inhibitor to retain hyalunonan in a stable complex. TSG-6, on the other hand, is expressed by cumulus and granulosa cells in response to the $\mathrm{LH}$ surge (Fulop et al., 1997b; Mukhopadhyay et al., 2001), and it also binds hyaluronan (Mahoney et al., 2001) and inter- $\alpha$-trypsin inhibitor (Carrette et al., 2001; Ochsner et al., 2003) or chondroitin-4-sulphate side chains of proteoglycans (Parkar and Day, 1997), such as found on versican, and these interactions may also be important for COC expansion.

The importance of these molecules and the stabilization of the matrix of the COC by cross-linking is further underscored by the loss of fertility associated with gene mutations. Mutation of the $C O X-2$ or $E P_{2}$ prostaglandin receptor genes results in reduced TSG- 6 expression in the COC (Ochsner et al., 2003), as well as impaired expansion of the COC and fertility. Although inter- $\alpha$ trypsin inhibitor is not normally limiting for expansion of the cumulus-oocyte matrix, mutation of the bikunin gene results in loss of circulating inter- $\alpha$-trypsin inhibitor. 
This causes impaired expansion of the COC and hence reduced fertility (Zhuo et al., 2001). The COC matrix probably anchors to cumulus cells and the oocyte via the cell surface hyaluronan-binding receptor, CD44 (Kimura et al., 2002), and possibly through interaction of integrins with matrix proteins such as versican. Clearly the exact composition, structure and necessary functional moieties of the expanded COC matrix need further investigation to clarify the nature and role of all matrix molecules.

Other matrix proteins are important, not specifically for the expansion of the matrix after $\mathrm{LH}$ surge, but for proper functioning of the COC itself. The zona pellucida of the oocyte is a very specialized extracellular matrix composed of a number of oocyte-secreted glycoproteins (ZP1, ZP2 and ZP3). The zona pellucida is important for fertilization and this has been reviewed many times (Dunbar et al., 1994; Wassarman et al., 1996; Rankin et al., 2000). Disruption of zona pellucida formation either by gene 'knockout' in mice or by immunization show that the zona pellucida is required for normal follicular development, and particularly the formation of a proper COC (Rankin et al., 2000). Additional protein products of the $\mathrm{COC}$ may be incorporated into the expanded COC matrix and may function to protect its integrity. Pentraxin-3 is a product of cumulus cells induced by growth differentiation factor 9 derived from the oocyte (Varani et al., 2002). Deficiency of the pentraxin-3 is detrimental to matrix stability of the COC ovulation and fertilization (Varani et al., 2002).

\section{Extracellular matrix of the thecal layers}

Laminin $\gamma 1$ chain, laminin 1 components $(\alpha 1$ or $\beta 1$ or $\gamma 1)$ (van Wezel et al., 1998) and collagen type IV $\alpha 1$ and $\alpha 2$ (Rodgers HF et al., 1998) are present in bovine follicles throughout the theca interna and not in association with any conventional basal laminae, such as those of blood vessels. At the electron microscope level, fragments of basal lamina-like, electron-dense material have been observed and this matrix has been named the 'thecal matrix' (Rodgers et al., 2000). In other species, such as mice and rats, a similar matrix has been observed in the theca and in the interstitial tissue of developing gonads by localizing laminin 1 components. The origins and functions, if any, of the thecal matrix are not known.

A number of basal laminae are present in the theca, sub-endothelial basal laminae and those surrounding smooth muscle cells of arterioles (see Table 1). The blood vessels in the theca of the rat contain collagen type IV $\alpha 1$ and $\alpha 2$ (Frojdman et al., 1998). The presence of multiple basal laminae throughout the thecal layers makes it difficult to study the expression of basal lamina components when relying solely on RNA analyses or western blot analyses of the thecal layers.

As the theca interna and externa are stromal layers, other types of matrix component are present. Structural collagens have been observed in the theca externa of many species, and collagen type I has been identified (Luck et al., 1995; Zhao and Luck, 1995). Collagen type VI, involved in the organization of fibronectin extracellularly, has also been identified in the theca interna (Iwahashi et al., 2000).

\section{Common extracellular matrix components}

Hyaluronan, versican and fibronectin are found in more than one compartment in the follicle. The biology of versican and hyaluronan are discussed above. Fibronectin, like versican, is also widely distributed. It too has domains enabling it to interact with other matrix components (fibrin, collagen, heparin) and cell-surface integrins. Fibronectin is commonly a matrix of stroma and it is important for cell migration, which must clearly occur during expansion of the theca during follicular development. In humans, at least 20 different isoforms of fibronectin are present, due to alternative splicing of mRNA at three separate sites (extra domain $A(E D A), E D B$, and the variable $(V)$ region). Fibronectin occurs as a homo- or heterodimer of these splice variants. A number of the splice variants are expressed in follicles (De Candia and Rodgers, 1999), and the EDA domain of fibronectin has been shown to be mitogenic for granulosa cells in vitro (Colman-Lerner et al., 1999), and fibronectin synthesis by granulosa cells can be upregulated by FGF2 (Rodgers et al., 1996). There is a considerable number of publications localizing fibronectin in ovaries, often as a result of using antibodies that recognize all forms of fibronectin. There does not appear to be a consistent pattern across species, with reports of fibronectin, usually of an undefined type, being localized to different follicle compartments. All these reports may well be accurate. However, there is also a circulating form of fibronectin lacking EDB and EDA domains. In many of the studies of ovaries, the antibodies used would react with all the isoforms of fibronectin. Thus, more studies are required to identify the precise expression patterns of fibronectin isoforms during follicle development. A very careful analysis of the differential splicing of fibronectin is required if its correct role during follicle development is to be discovered.

\section{Conclusions}

The study of the extracellular matrix in many other organs of the body, and indeed much of the cellular biology, is more advanced than it is for ovaries. However, the studies in other organs have provided a vast body of knowledge and reagents with which to study the extracellular matrix in the ovary. Matrix components are already being identified, localized and correlated with different stages of follicular and luteal development. More importantly, the precise isoforms are now being identified in ovaries. Future research will no doubt focus on the origins and regulation of synthesis of the matrix components in the 
ovary. Studies of the effects of the molecules on cell or tissue behaviour have also commenced, but currently most of these studies use matrix components that are related only to those found in the ovary. Although they are useful in identifying behaviours that the matrix can control, ultimate proof of their roles will come only from using or mimicking the native matrix molecules. In addition, more sophisticated cell culture conditions or systems will be required. Many of the current methods were established with only endocrine parameters in mind. Other approaches, using genomic mutations, such as those successfully being used to study the zona pellucida, may independently shed light upon the roles of the matrix in ovarian function. In summary, in recent years there has been a considerable increase in our knowledge on this subject and the next few promise to produce results equally exciting.

Research in the authors' laboratories has been supported by the National Health and Medical Research Council of Australia, Adelaide University, Wellcome Foundation, Clive and Vera Ramaciotti Foundation, and the National Institutes of Health.

\section{References}

Key references are identified by asterisks.

Antczak M and Van Blerkom J (2000) The vascular character of ovarian follicular granulosa cells: phenotypic and functional evidence for an endothelial-like cell population Human Reproduction 15 2306-2318

Asem EK, Qin W and Rane SG (2002) Effect of basal lamina of ovarian follicle on T- and L-type $\mathrm{Ca}^{(2+)}$ currents in differentiated granulosa cells American Journal of Physiology Endocrinology and Metabolism 282 E184-E196

Belkin AM and Stepp MA (2000) Integrins as receptors for laminins Microscopy Research and Technique 51 280-301

Carnegie JA (1990) Secretion of fibronectin by rat granulosa cells occurs primarily during early follicular development Journal of Reproduction and Fertility 89 579-589

* Carrette O, Nemade RV, Day AJ, Brickner A and Larsen WJ (2001) TSG-6 is concentrated in the extracellular matrix of mouse cumulusoocyte complexes through hyaluronan and inter-alpha-inhibitor binding Biology of Reproduction 65 301-308

Champliaud MF, Virtanen I, Tiger CF, Korhonen $M$, Burgeson $R$ and Gullberg D (2000) Post-translational modifications and beta/gamma chain associations of human laminin alpha 1 and laminin alpha5 chains: purification of laminin-3 from placenta Experimental Cell Research 259 326-335

Chen L, Zhang H, Powers RW, Russell PT and Larsen WJ (1996) Covalent linkage between proteins of the inter-alpha-inhibitor family and hyaluronic acid is mediated by a factor produced by granulosa cells Journal of Biological Chemistry 27119 409-19 414

Colman-Lerner A, Fischman ML, Lanuza GM, Bissell DM, Kornblihtt AR and Baranao JL (1999) Evidence for a role of the alternatively spliced ED-I sequence of fibronectin during ovarian follicular development Endocrinology 140 2541-2548

Curry TE and Osteen KG (2001) Cyclic changes in the matrix metalloproteinase system in the ovary and uterus Biology of Reproduction 64 1285-1296

D'Alessandris C, Canipari R, Di Giacomo M, Epifano O, Camaioni A, Siracusa G and Salustri A (2001) Control of mouse cumulus cell-oocyte complex integrity before and after ovulation: plasminogen activator synthesis and matrix degradation Endocrinology 142 3033-3040

De Candia LM and Rodgers RJ (1999) Characterisation of alternative splicing of ED-A, ED-B and $V$ regions of fibronectin mRNA in bovine ovarian follicles and corpora lutea Reproduction, Fertility and Development $\mathbf{1 1}$ 367-377

Dunbar BS, Avery S, Lee V, Prasad S, Schwahn D, Schwoebel E, Skinner S and Wilkins B (1994) The mammalian zona pellucida: its biochemistry, immunochemistry, molecular biology, and developmental expression Reproduction, Fertility and Development 6 331-347

Eriksen GV, Carlstedt I, Morgelin M, Uldbjerg N and Malmstrom A (1999) Isolation and characterization of proteoglycans from human follicular fluid Biochemistry Journal 340 613-620

Frojdman K, Ekblom P, Sorokin L, Yagi A and Pelliniemi LJ (1995) Differential distribution of laminin chains in the development and sex differentiation of mouse internal genitalia International Journal of Developmental Biology 39 335-344

Frojdman K, Pelliniemi LJ and Virtanen I (1998) Differential distribution of type IV collagen chains in the developing rat testis and ovary Differentiation 63 125-130

Fujiwara $H$, Honda $T$, Ueda $M$, Nakamura $K$, Yamada $S$, Maeda $M$ and Mori T (1997) Laminin suppresses progesterone production by human luteinizing granulosa cells via interaction with integrin alpha 6 beta 1 Journal of Clinical Endocrinology and Metabolism 82 2122-2128

Fulop C, Salustri A and Hascall VC (1997a) Coding sequence of a hyaluronan synthase homologue expressed during expansion of the mouse cumulus-oocyte complex Archives of Biochemistry and Biophysics 37 261-266

Fulop C, Kamath RV, Li Y, Otto JM, Salustri A, Olsen BR, Glant TT and Hascall VC (1997b) Coding sequence, exon-intron structure and chromosomal localization of murine TNF-stimulated gene 6 that is specifically expressed by expanding cumulus cell-oocyte complexes Gene 202 95-102

Gilbert AB, Evans AJ, Perry MM and Davidson MH (1977) A method for separating the granulosa cells, the basal lamina and the theca of the preovulatory ovarian follicle of the domestic fowl (Gallus domesticus) Journal of Reproduction and Fertility 50 179-181

Hay ED (1991) Cell Biology of Extracellular Matrix 2nd Ed. Plenum Press, New York

Hess KA, Chen L and Larsen WJ (1998) The ovarian blood follicle barrier is both charge- and size-selective in mice Biology of Reproduction $\mathbf{5 8}$ 705-711

Hess KA, Chen L and Larsen WJ (1999) Inter-alpha-inhibitor binding to hyaluronan in the cumulus extracellular matrix is required for optimal ovulation and development of mouse oocytes Biology of Reproduction 61 436-443

Huet C, Monget P, Pisselet C and Monniaux D (1997) Changes in extracellular matrix components and steroidogenic enzymes during growth and atresia of antral ovarian follicles in the sheep Biology of Reproduction 56 1025-1034

Irving-Rodgers HF, van Wezel IL, Mussard ML, Kinder JE and Rodgers RJ (2001) Atresia revisited: two basic patterns of atresia of bovine antral follicles Reproduction 122 761-775

Irving-Rodgers HF, Mussard ML, Kinder JE and Rodgers RJ (2002) Composition and morphology of the follicular basal lamina during atresia of bovine antral follicles Reproduction 123 97-106

Iwahashi M, Muragaki Y, Ooshima A and Nakano R (2000) Type VI collagen expression during growth of human ovarian follicles Fertility and Sterility 74 343-347

Kimura N, Konno Y, Miyoshi K, Matsumoto H and Sato E (2002) Expression of hyaluronan synthases and CD44 messenger RNAs in porcine cumulus-oocyte complexes during in vitro maturation Biology of Reproduction 66 707-717

Le Bellego F, Pisselet C, Huet C, Monget P and Monniaux D (2002) Lamininalpha6beta1 integrin interaction enhances survival and proliferation and modulates steroidogenesis of ovine granulosa cells Journal of Endocrinology 172 45-59

Lefebvre O, Sorokin L, Kedinger $\mathbf{M}$ and Simon-Assmann P (1999) Developmental expression and cellular origin of the laminin alpha2, alpha4, and alpha5 chains in the intestine Developmental Biology 210 135-150

Luck MR (1994) The gonadal extracellular matrix Oxford Reviews of Reproductive Biology 16 33-85 
Luck MR, Zhao Y and Silvester LM (1995) Identification and localization of collagen types I and IV in the ruminant follicle and corpus luteum Journal of Reproduction and Fertility Supplement 49 517-521

McArthur ME, Irving-Rodgers HF, Byers S and Rodgers RJ (2000) Identification and immunolocalisation of decorin, versican, perlecan, nidogen, and chondroitin sulfate proteoglycans in bovine small ovarian follicles Biology of Reproduction 63 913-924

Mahoney DJ, Blundell CD and Day AJ (2001) Mapping the hyaluronanbinding site on the link module from human tumor necrosis factorstimulated gene- 6 by site-directed mutagenesis Journal of Biological Chemistry $27622764-22771$

Miosge N, Sasaki T and Timpl R (2002) Evidence of nidogen-2 compensation for nidogen-1 deficiency in transgenic mice Matrix Biology 21 611-621

Mukhopadhyay D, Hascall VC, Day AJ, Salustri A and Fulop C (2001) Two distinct populations of tumor necrosis factor-stimulated gene- 6 protein in the extracellular matrix of expanded mouse cumulus cell-oocyte complexes Archives of Biochemistry and Biophysics 394 173-181

Ochsner SA, Russell DL, Day AJ, Breyer RM and Richards JS (2003) Decreased expression of tumor necrosis factor-alpha-stimulated gene 6 in cumulus cells of the cyclooxygenase-2 and EP2 null mice Endocrinology 144 1008-1019

Odum L, Andersen CY and Jessen TE (2002) Characterization of the coupling activity for the binding of inter-alpha-trypsin inhibitor to hyaluronan in human and bovine follicular fluid Reproduction 124 249-257

Parkar AA and Day AJ (1997) Overlapping sites on the Link module of human TSG-6 mediate binding to hyaluronan and chrondroitin-4sulphate FEBS Letters 410 413-417

Paulsson M (1992) Basement membrane proteins: structure, assembly, and cellular interactions Critical Reviews of Biochemistry and Molecular Biology 27 93-127

Powers RW, Chen L, Russell PT and Larsen WJ (1995) Gonadotropinstimulated regulation of blood-follicle barrier is mediated by nitric oxide American Journal of Physiology 269 E290-E298

Rankin T, Soyal S and Dean J (2000) The mouse zona pellucida: folliculogenesis, fertility and pre-implantation development Molecular and Cellular Endocrinology $16321-25$

Rapp G, Freudenstein J, Klaudiny J, Mucha J, Wempe F, Zimmer M and Scheit KH (1990) Characterization of three abundant mRNAs from human ovarian granulosa cells DNA Cell Biology 7 479-485

Rodgers HF, Lavranos TC, Vella CA and Rodgers RJ (1995) Basal lamina and other extracellular matrix produced by bovine granulosa cells in anchorage-independent culture Cell and Tissue Research $\mathbf{2 8 2}$ $463-471$

Rodgers RJ, Vella CA, Rodgers HF, Scott K and Lavranos TC (1996) Extracellular matrix production by and the behaviour of bovine granulosa cells in anchorage-independent culture Reproduction, Fertility and Development 8 249-257

* Rodgers HF, Irvine CM, van Wezel IL, Lavranos TC, Luck ML, Sado Y, Ninomiya Y and Rodgers RJ (1998) Distribution of the $\alpha 1$ to $\alpha 6$ chains of type IV collagen in bovine follicles Biology of Reproduction 591334 1341

Rodgers RJ, van Wezel IL, Rodgers HF, Lavranos TC, Irvine CM and Krupa M (1998) Developmental changes in cells and matrix during follicle growth. In Gametes: Development and Function Eds A Lauria, F Gandolfi, G Enne and I Gianaroli. Serono Symposia

Rodgers RJ, Lavranos TC, van Wezel IL and Irving-Rodgers HF (1999a) Development of the ovarian follicular epithelium Molecular and Cellular Endocrinology 151 171-179

Rodgers RJ, van Wezel IL, Rodgers HF, Lavranos TC, Irvine CM and Krupa M (1999b) Roles of extracellular matrix in follicular development Journal of Reproduction and Fertility Supplement 54 343-352

Rodgers RJ, Irving-Rodgers HF and van Wezel IL (2000) Extracellular matrix in ovarian follicles Molecular and Cellular Endocrinology 163 73-79

Rodgers RJ, Irving-Rodgers HF, van Wezel IL, Krupa M and Lavranos TC (2001) Dynamics of the membrana granulosa during expansion of the ovarian follicular antrum Molecular and Cellular Endocrinology 171 $41-48$
*Russell DL, Ochsner SA, Hsieh M, Mulders S and Richards JS (2003) Hormone-regulated expression and localization of versican in the rodent ovary Endocrinology 144 1020-1031

Sado Y, Kagawa M, Naito I, Ueki Y, Seki T, Momota R, Oohashi T and Ninomiya $\mathbf{Y}$ (1998) Organization and expression of basement membrane collagen IV genes and their roles in human disorders Journal of Biochemistry 123 767-776

Salustri A, Yanagishita M, Underhill CB, Laurent TC and Hascall VC (1992) Localization and synthesis of hyaluronic acid in the cumulus cells and mural granulosa cells of the preovulatory follicle Developmental Biology 151 541-551

Sandy JD, Westling J, Kenagy RD et al. (2001) Versican V1 proteolysis in human aorta in vivo occurs at the Glu441-Ala442 bond, a site that is cleaved by recombinant ADAMTS-1 and ADAMTS-4 Journal of Biological Chemistry 27613 372-13 378

Sawyer HR, Smith P, Heath DA, Juengel JL, Wakefield SJ and McNatty KP (2002) Formation of ovarian follicles during fetal development in sheep Biology of Reproduction 66 1134-1150

Schoenfelder M and Einspanier R (2003) Expression of hyaluronan synthases and corresponding hyaluronan receptors is differentially regulated during oocyte maturation in cattle Biology of Reproduction 69269 277

Shalgi R, Kraicer P, Rimon A, Pinto M and Soferman N (1973) Proteins of human follicular fluid: the blood-follicle barrier Fertility and Sterility $\mathbf{2 4}$ 429-434

Smith MF, McIntush EW, Ricke WA, Kokijima FN and Smith GW (1999) Regulation of ovarian extracellular matrix remodelling by metalloproteinases and their tissue inhibitors: effects on follicular development, ovulation and luteal function Journal of Reproduction and Fertility Supplement 54 367-381

Sorokin LM, Pausch F, Durbeej M and Ekblom P (1997) Differential expression of five laminin alpha (1-5) chains in developing and adult mouse kidney Developmental Dynamics 210 446-462

Sun GW, Kobayashi H, Suzuki M, Kanayama N and Terao T (2002) Link protein as an enhancer of cumulus cell-oocyte complex expansion Molecular Reproduction and Development 63 223-231

Timpl R (1989) Structure and biological activity of basement membrane proteins European Journal of Biochemistry 180 487-502

Timpl R and Brown JC (1996) Supramolecular assembly of basement membranes BioEssays 18 123-132

*van Wezel IL, Rodgers HF and Rodgers RJ (1998) Differential localization of laminin chains in the bovine follicle Journal of Reproduction and Fertility 112 267-278

van Wezel IL, Rodgers HF, Sado Y, Ninomiya Y and Rodgers RJ (1999) Ultrastructure and composition of Call Exner bodies in bovine follicles Cell and Tissue Research 296 385-394

Varani S, Elvin JA, Yan C, DeMayo J, DeMayo FJ, Horton HF, Byrne MC and Matzuk MM (2002) Knockout of pentraxin 3, a downstream target of growth differentiation factor-9, causes female subfertility Molecular Endocrinology 16 1154-1167

Wassarman PM, Liu C and Litscher ES (1996) Constructing the mammalian egg zona pellucida: some new pieces of an old puzzle Journal of Cell Science 109 2001-2004

Weber M (1992) Basement membrane proteins Kidney International 41 620-638

Yoshioka S, Ochsner S, Russell DL, Ujioka T, Fujii S, Richards JS and Espey LL (2000) Expression of tumor necrosis factor-stimulated gene- 6 in the rat ovary in response to an ovulatory dose of gonadotropin Endocrinology 141 4114-4119

Yurchenco PD and Schittny JC (1990) Molecular architecture of basement membranes FASEB Journal 4 1577-1590

Zhao Y and Luck MR (1995) Gene expression and protein distribution of collagen, fibronectin and laminin in bovine follicles and corpora lutea Journal of Reproduction and Fertility 104 115-123

Zhuo L, Yoneda M, Zhao M, Yingsung W, Yoshida N, Kitagawa Y, Kawamura K, Suzuki T and Kimata K (2001) Defect in SHAP-hyaluronan complex causes severe female infertility. A study by inactivation of the bikunin gene in mice Journal of Biological Chemistry 276 7693-7696 